\title{
Treatment of patients with spinal cord lesions in Germany 1996 - State of the art
}

\author{
F-W Meinecke ${ }^{1}$ and G Exner ${ }^{2}$ \\ ${ }^{1}$ Krummwisch 6, D-21465 Reinbek; ${ }^{2}$ Berufsgenossenschaftliches Unfallkrankenhaus - Querschnittgelähmten - Zentrum \\ - Bergedorfer Str 10 D-21033 Hamburg, Germany
}

\begin{abstract}
Modern treatment of sufferers from spinal cord lesions according to the guidelines elaborated by Sir Ludwig Guttmann in the UK started in specialised centres in Germany some 45 years ago. At the present time the incidence is 18 cases/1 million/year traumatic and non traumatic. Exact figures are available since 20 years ago. Twenty-one appropriate centres with altogether 1071 beds are able to admit almost all traumatic cases and $30 \%$ of non traumatic cases for 'comprehensive treatment'. That includes cervical lesions above $\mathrm{C} 4$ as well as patients with polytrauma, intensive care, spinal column surgery, sophisticated urological diagnostic and treatment, physio- and occupational therapy, psychological and social assistance. To fulfil all tasks arising from lifetime care and readmissions there is a need of another 800 beds in specialised centres not dealing with recent cases. The original principle to offer first treatment and life-time follow up 'under one roof' is to be given up as conservative treatment of the broken spine has been continually replaced by spinal surgery done in non specialised primary admitting regional hospitals. Priority is given to the aim to offer similar opportunities to everyone by providing 800 additional beds in new specialised centres.
\end{abstract}

Keywords: spinal cord lesions; comprehensive treatment; organisation; present situation; Germany

\section{Introduction}

Modern treatment of patients with spinal cord lesions in Germany according to the rules developed and layed down by Sir Ludwig Guttmann in the UK since 1942 started in Germany in the early fifties by some special units (SCIC) mainly being part of accident hospitals run by the workmen's compensation board (WCB). They were followed by construction of SCICs within other hospitals during the following years. The number of centres in the former Federal Republic of Germany in 1989 was 16 with an overall capacity of 778 beds. In the former German Democratic Republic (GDR) there existed at that time two centres with an overall capacity of 101 beds.

In the FRG the principle was to admit recent patients as soon as possible by a SCIC in order to provide 'comprehensive treatment' from the very beginning up to the end 'under one roof'. That was quite different from other countries using a split system, like Austria or the USA divided into the 'acute stage' and the 'rehabilitation phase'. In the GDR selected cases only were admitted by the two centres following the early treatment.

Correspondence: F-W Meinecke

\section{Present situation}

Spinal cord injuries centres

There exist after the reunification of both parts of Germany altogether 21 SCICs with an overall capacity of 1071 beds. Two centres in the eastern part are to be closed in 1997. They will be replaced by two new units with 60 beds each in Berlin and Halle run by the WCB. Other SCICs are in progress at the University of Greifswald (42 beds) and in Bad Berka (60 beds). That would raise the overall capacity to 1172 beds. This number does not cope with all recent cases and readmissions necessary. All patients of the WCB's responsibility-that means work connected injurieswill find a chance to be admitted by a SCIC belonging to the Workmen's Compensation Accident Insurance that is about $15-20 \%$ of all admissions. In the last memorandum of the WCB in 1995 dealing with these problems as well as with organisational and architectural suggestions and guidelines the German specialists call for altogether 1900 beds within a net of efficient units all over Germany. ${ }^{1}$ The 1976 opened 'Bed Procurement Bureau for Patients with recent Spinal Cord Lesions' (Clearing Agency $=\mathrm{CA})^{2}$ working at the SCIC Hamburg tries to support physicians of general hospitals in finding an adequate treatment in a specialised centre. Details will be given by Exner and Meinecke see $\mathrm{p} 411$. The incidence of recent traumatic 
and non traumatic cases today is 18 cases/1 million inhabitants/year.

\section{Early treatment}

The rescue system in Germany provides a net of first aid teams by helicopter. These flying services cover the entire country. On an average they need $8-10 \mathrm{~min}$ to reach any scene of an accident. All professional people and many non professional people are well trained in first aid, in particular in resuscitation (mouth to mouth breathing). By this more and more patients arrive in hospitals alive with high cervical lesions (above $\mathrm{C} 4$ ) or with associated injuries dangerous to life. Sometimes they remain at the primary admitting hospital. Meanwhile spinal surgery became more and more common in this country and is done in many non specialised hospitals. Those patients also will be kept in the primary hospital. As long as spinal column treatment was conservative the general hospitals were not interested to keep tetra- or paraplegics. They asked the SCICs for admittance immediately. That was the basis for the 'comprehensive treatment under one roof' in former years. Spinal surgery done elsewhere is the basis of the modern split treatment. Immediate admission of recent cases by a SCIC decreased during the last 5-8 years. This delay sometimes results in avoidable complications of skin, urinary tract and locomotor system. The medico-legal system development with introducing new regulations in this country is another danger in destroying the traditional good experiences.

Intensive care increases the survival rate of those with recent injuries, in particular in multiple injuries (polytrauma) and upper cervical lesions. Most of the recent cases are at first admitted by these special departments. On the other hand the small number of beds available and patients' long stay restricts the capacity and flexibility as well of these intensive care units as of the SCICs.

As soon as the patient is not at risk, the question of spinal fusion arises. New diagnostic procedures (ie CT) and surgical experiences resulted in a better understanding of different types of spinal injuries with special classification systems. In combination with longtime follow up it resulted in developing of different stabilisation devices and surgical procedures adapted to the special types of injuries. This became the method of choice under modern conditions. The aims are good realignment of the spine, early stability for exercises and mobilisation.

Whether or not early decompression results in better conditions for neurological recovery is still questionable. Up to now there is no proof of better regeneration of the spinal cord by early surgical interventions. Time of hospitalisation is dependent on many individual factors, it may be shortened. In the Hamburg Centre in 1990 the average time of hospitalisation for tetraplegic patients was 168 days, regardless whether the spinal treatment was surgical or conservative. In paraplegic patients it was 178 days after conservative and 132 days after surgical treatment. Early stabilisation facilitates primary nursing, physio- and vocational therapy and shortens time of bedrest to $8-14$ days. These are great advantages.

Cervical lesions above $\mathrm{C} 4$ are a new challenge in many respects. They are treated in special wards as in Bad Wildungen and Hamburg or in general SCICwards as in Bayreuth, Bochum or Ulm. Electrostimulation of the diaphragm or the phrenic nerves tries to avoid permanent artificial respiration by respirators and tracheostomy. This system was started in 1982 in Bad Wildungen.

\section{Urinary tract}

The treatment of the urinary tract has changed very much within the last 20 years. Urology is now a very important part of the entire treatment. In 1978 urologists created the speciality 'Neuro-Urology' with a special working group. Autonomous neuro-urological departments exist in Bad Wildungen and Murnau, in Hamburg it is part of the SCIC. The treatment tends to provide a balanced bladder for lifetime. It starts with the use of thin suprapubic catheters changing to intermittent catheterisation and-if possible-intermittent selfcatheterisation. Intensive and regular repeated urodynamic investigations clarify the individual situation. In case of a spastic bladder function anticholinergic treatment (ie Oxybutynin) is started in any patient when indicated and possible in connection with intermittent catheterisation. The decision for the final treatment will be made after some further observation. Partial sphincterotomy is less in use. Later on the indication for electrostimulation of the bladder according to Brindley in combination with sacral deafferentation according to Sauerwein (see p456) is under discussion. Here we refer to the paper of $M$ Stöhrer et al dealing with bladder autoaugmentation in this issue.

\section{Sexual function-fertility}

This manifold complex has received increasing attention by physicians and psychologists and is a special part in regular counselling seminars for patients and relatives. The neuro-urological department in Murnau focused a great part of its work in sexual rehabilitation with remarkable success. In this connection we refer to the paper of D Löchner-Ernst et al see p463. For erectile dysfunction in paraplegics there are mechanical devices in use, ie rings, implantable semirigid or inflatable penis prostheses. Another procedure is the intracavernous injection of vasoactive drugs (papaverin plus phentolamine).

\section{Internal medicine}

Survival expectancy is in close relation to respiratory and cardiovascular function. This is mainly part of 
intensive care in the early stage in order to stabilise these vital functions. This is in close connection with the function of the autonomic nervous system. Prophylactic programs to avoid deep vein thrombosis or pulmonary emboli are a little bit different in the various places but consist of early mobilisation, anticoagulant therapy and bandaging with support stockings. There are many other tasks of medical care not different from treatment of the general population. So far there are no special departments of internal medicine as part of spinal units.

\section{Neurology}

Aside from some special indications such as brain injuries, spinal cord tumors or psychiatric disorders there is no special diagnostic procedure or treatment for neurologists within the entire comprehensive treatment program. Neurologists may confirm the neurological examination done by physicians of the SCIC. Neurologists are involved in follow ups, in treatment of spasticity and in special investigations. There is no special neurological department within a SCIC, but the head of the SCIC in Bayreuth is a neurologist himself.

\section{General remarks}

Internal specialists, neurologists and urologists are mainly working as consultants as ophthalmologists and otolaryngologists do. Most SCICs are part of accident or general hospitals with special surgical, orthopedic and $\mathrm{x}$-ray departments, laboratories etc included.

\section{Physiotherapy}

PT starts immediately at the intensive care units in close cooperation with the specialised medical and nursing staff regardless whether or not the patient is under artificial respiration. In the last years they developed special techniques for patients with lesions above $\mathrm{C} 4$ in order to improve respiration by using the auxiliary musculature or electrostimulation of the diaphragm or phrenic nerves. In general some special techniques as PNF or Vojta, sometimes functional electrostimulation (FES) and locomotion treatment ('Laufband') are used. In spasticity later on attempts are made to help by horse riding therapy and in severe cases by intrathecal injections of baclofen via implanted pumps.

\section{Occupational therapy}

The main concern is to start as early as possible any kind of communication with patients intubated or on tracheostoma. Beside that it is the aim to bring patients, in particular tetraplegics to the highest possible level of independence by training with and without technical aids (ADL).
Nursing staff

Basic nursing according to the general rules has not changed. Special systems are developing in the care of tetraplegics above $\mathrm{C} 4$, which nearly comes into the sphere of intensive care.

\section{Psychology}

Psychological problems arise not only with patients and their relatives but also with staff members of any profession. This is particularly true for all people when treating high cervical lesions. Today many centres are running permanent psychological services as part of the entire team. Psychologists developed their special guidelines to cope with the manifold tasks in a SCIC.

\section{Social services}

Social workers are permanent team members in most SCIC. As legislation is changing very quickly and intensively in this country during the last years it is a very difficult and sophisticated job dealing with financial problems, housing, nursing care etc at the end of the first treatment. This takes a lot of time, as many different bodies are responsible for many things. This is quite different from patients belonging to the WCB. This is a liability insurance against occupational accidents or diseases for employees and workers paid by employers. By that it is responsible for everything needed may be by treatment, equipment, housing, cars etc. They employ special social workers ('case managers' or 'Berufshelfer') either in their hospitals or as part of the administration responsible visiting their patients in hospital.

\section{Discussion}

The system described demonstrates the present situation. We mentioned those facts only, which are from our point of view either new or typical of the situation in Germany. We dealt with traumatic lesions mainly. We do feel, that the existing centres are able to cope with and admit all recent cases of traumatic origin. The number of unknown unaccounted cases seems to be small. Spinal Cord lesions of non traumatic origin can be admitted only if there are any vacancies. Many who inquire have to be refused for lack of capacity. The non traumatic group comprises a large unknown number of unaccounted cases. This is a big problem. Readmissions for lifetime care or for treatment of complications are only available for patients belonging to the $\mathrm{WCB}$ in their centres. This is impossible for all patients belonging to any sickness or social insurance. The heads of the centres in Germany try to improve this unsatisfactory situation by repeated calls and suggestions to set up new centres dealing with readmissions and lifetime care only. They can also take care of non traumatic cases such as myelitis, tumors etc as soon as the primary 
basic treatment in neurological or neurosurgical departments has been finished.

Improved survival rate and life expectancy increases the number of paralysed people year by year. Children with congenital lesions such as spina bifida are growing up, so that pediatricians cannot take care for them becoming adults. They need lifetime care by specialists like the other group of paralysed people. But the existing SCICs cannot provide sufficient treatment. This could be done as out- or inpatients by well equipped centres which do not admit recent cases. That means two types of spinal centres are needed:

1 Centres responsible for the overall treatment of any kind of spinal paresis (recent traumatic and non traumatic cases, readmissions for check-ups, lifetime care and complications, out-patients.)

2 Centres dealing with all kinds of spinal lesions except recent cases, to carry out primary treatment as soon as the patient is fully mobilised, for readmissions and out-patients as described under 1 . The overall situation, the needs for the future suggestions for architectural and staff programs are again described in the 3rd edition of the memorandum 'Zur Neuordnung der Behandlungszentren für Querschnittgelähmte in der Bundesrepublik Deutschland mit Planungsrichtwerten für Neubauten' 1995 published by the WCB. ${ }^{1}$ It is based on the experiences and figures collected within 20 years by the 'AC' and the connected working group.

The present situation is best described within the proceedings of the different scientific meetings of the 'Deutschsprachige Medizinische Gesellschaft für Paraplegie' (DMGP) since 1989. ${ }^{3-8}$ They include presentations of all aspects of the comprehensive treatment and organisation reported by members of all professions concerned. The majority of the papers are published in German, so we may refer to the reference list of the articles published in this issue. In summary they give an impression about what is going on in Germany.

\section{Conclusions}

The present situation in Germany offers optimal conditions for almost all sufferers from recent traumatic spinal cord lesions, as they will be admitted by specialised centres (SCIC) as soon as possible. Treatment is according to the modern international standards in any respect. Due to a shortage of appropriate facilities for all patients, except people insured by the WCB, there exists a deficit in order to meet their needs with treatment facilities for non traumatic cases and lifetime care for a great part paralysed people except patients belonging to the WCB. Specialists in this field follow all modern aspects of comprehensive treatment medical, social, psychological. In close cooperation with administrators and politicians they are trying to improve the general situation for all paralysed people, regardless of what origin and which responsible insurance agency and whether there is a recent or chronic paralysis.

\section{References}

1 Hauptverband der gewerblichen Berufsgnossenschaften. Zur Neuordnung der Behandlungszentren für Querschnittgelähmte in der Bundesrepublik Deutschland mit Planungsricht-werten für Neubauten. 3. Aufl. St. Augustin 1995.

2 Meinecke F-W. Two years of bed procurement for patients with spinal cord lesions. Paraplegia 1979; 17: 62-72.

3 Grüninger W (ed). Spinale Spastik. Ueberreuter Wissenschaft, Wien Berlin 1989.

4 Meinecke F-W (ed). Querschnittlähmungen, Springer, Berlin Heidelberg 1990.

5 Zäch GA (ed) Rehabilitation beginnt am Unfallort. Springer, Berlin Heidelberg 1992.

6 Walker N (ed). Langzeitverläufe und Spätresultate bei Querschnittlähmung. Springer, Berlin Heidelberg 1994.

7 Jonas HP, Madersbacher H, Strubreither W (eds). Der polytraumatisierte Querschnittgelähmte, Allgemeine Unfallversicherungsanstalt, Wien 1995.

8 Gerner HJ (ed). Querschnittlähmungen, Springer, Berlin, Heidelberg 1996. 